International Journal of Engineering \& Technology, $7(2.29)(2018) 586-592$
SPC
Website www.sciencepubco.com/index.php/IJET
Research paper

\title{
Drought Risk Assessment Using Remote Sensing and GIS in Yemen
}

\author{
Ali Ahmed Ali Dhaifallah" ${ }^{1 *}$ Noorazuan Bin MD. Hashim², Azahan Bin Awang ${ }^{3}$ \\ ${ }^{1}$ Geography Department, Faculty Of Arts, Thamar University, Thamar, Yemen \\ ${ }^{2}$ School Of Social, Development And Environmental Studies, Faculty Of Social Sciences And Humanities, \\ Universiti Kebangsaan Malaysia, 43600 Bangi, Selangor, Malaysia \\ ${ }^{3}$ School Of Social, Development And Environmental Studies, Faculty Of Social Sciences And Humanities, \\ Universiti Kebangsaan Malaysia, 43600 Bangi, Selangor, Malaysia \\ *Corresponding Author E-Mail: Aali10102010@Gmail.Com
}

\begin{abstract}
Drought remains the most frequent and serious environmental threat in the Middle East area. In Yemen, drought has negatively been affecting both livelihood and sustainable development of the country. This research aims to monitoring and assessing the drought risk through the changes in vegetation cover and sand dunes deposit in Tihama Plain, Yemen using remote sensing and GIS. Landsat TM5 of 1985 and OLI8 of 2015 were used to evaluate the environmental indicators of drought using Normalized Difference Vegetation Index (NDVI) to recognize the progressive decline of vegetation based on the fact that vegetation absorbs red light and reflects infrared light of the electromagnetic spectrum. Through the index maps generated in a Geographic Information Systems (GIS) environment, the results showed that there was an increase of $26 \%$ in the area under severe drought during the period from 1985 to 2015 . Similarly, the areas under moderate drought also increased to approximately $64 \%$. On the other hand, areas under mild drought and those receiving normal rain experienced a decrease during the period as they gradually transformed into mild and severe drought situations. Within the study period, the area also recorded $74 \%$ increase in sand dunes deposit.
\end{abstract}

Keywords: Drought Risk; NDVI; Tihama Plain.

\section{Introduction}

Drought is one of the greatest destructive natural dangers for human, environmental and economic terms; it leads to water and food crisis, famines, human exodus, loss of human life, land degradation and low productivity of agricultural crops (1). Moreover, drought causes yearly a rate of \$6-8 billion of universal losses by natural catastrophes, and drought affects the livelihood of a large number of people more than the effect of any other type of natural disasters. These include humanitarian disasters, economic losses, and stresses on natural ecosystems across the globe (2). In addition to political and societal effects especially, in less economically developed nations that have limited adaptive capacity (3). For instance, between 1991-92, affected nearly 20 million of the population of South Africa as a result of the deficit in grain production due to drought, the deficit amounted to more than 6.7 million tons (4).

In many Arab countries, droughts have become a more frequent and a serious bluster to humanitarian safety. Over the last three decades, nearly 50 million people have been affected in the Arab region by climatic disasters events, with losses estimated at $\$ 11.5$ billion (5). It is a very hazardous problem which will increase causing serious threat on various aspects of life including humani- tarian disasters, economic losses, and stresses on natural ecosystems (6).

Over the last thirty years, Yemen experienced four periods of drought, 1979-1981, 1983- 1984, 1990-1991, 2007-2009 (7-9) caused a lot of damages on Yemeni economy, which largely relies on agricultural resources. According to the Ministry of Agriculture (2009), almost $73.5 \%$ of the population lives in rural areas and works in the agricultural sector, and thus significantly depends on appropriate weather conditions to their livelihoods. According to (10), the period of drought 1990-1991 was the worst in the modern history of Yemen because this period of drought synchronized with the Gulf war in 1991, which forced nearly 800,000 Yemeni workers to return to Yemen. Hence, workers' remittances decreased, leading to economic growth retreat, and growing the inflation rate and foreign debt, because of these negative effects decreased the possibility of Yemen to cope drought and mitigation.

During that period of drought, agricultural production reduced severely, economic growth has been affected due to the low agricultural production contribution in the gross domestic product. For instance, irrigated agriculture such as vegetables registered a decline in production by $16 \%$, as cereals yields dropped sharply, where production decreased both of millet, sorghum and barley by $33 \%, 34 \%$, and $38 \%$ respectively. As for livestock have witnessed 
a marked decrease by $11 \%$ as a result of the lack of pasture and forage due to drought (10). While that about $43 \%$ of the population living below the poverty line, according to the estimates of 2009. It is expected to increase the number of hungry people in Yemen between 80,000 - 270,000 people by 2050 (11), because of the severity of frequency of droughts and changing climate.

To the best knowledge of the researcher, there is no scientific study on drought in Yemen, as well as the lack of numbers that accurately describe how the drought affects the Yemenis $(8,12$, 13). However, there is information about the drought in Yemen found in non-local studies. These studies did not provide sufficient information on the drought in Yemen, they also did not address the drought indicators, through which on the duration, intensity and frequency of droughts in Yemen can be identified. What is reported in those studies is just general information, where no details about the causes, effects, and severity of drought in Yemen could touched. Therefore, the current study tries to bridge such a gap and as a first step to highlight the drought conditions in Yemen, as an attempt to ring the alarm bell to alert the dangers left behind by this serious phenomenon on the environment, economy and society.

This study will focus on the changes in vegetation cover (NDVI) and creeping of sand dunes to assess the drought risk in Tihama plain using remote sensing and GIS. By the fact that the study area is the most important agricultural areas in the country, it is necessary to study the changes in environmental indicators to know the drought conditions in the region. Therefore, two types of environmental indicators will be used, which

have a close and direct relationship with drought; these indicators are vegetation cover and sand dunes.

\section{Literature Review}

Drought is admittedly environmental hazard and attracted the attention of a lot of environmentalists, ecologists, meteorologists, hydrologists, and agricultural scientists (14). However, a lot of confusion remains there about the characteristics of drought due to the lack of exact and universally accepted definition. Therefore, many definitions for drought have been submitted according to the fields of interest (15). Additionally, there are several classifications developed for droughts most of which are characterized as meteorological drought, hydrological drought, agricultural drought and socio-economic drought. Realistically, definitions of "drought must be region, application, or impact specific". This is one explication for tens of definitions that have been advanced for drought (16).

Drought is the most complex of all natural hazards, despite the attempts at unification, several definitions of drought continue to be employed (17). For instance, (18) defined drought as a sustained period of time without significant rainfall. While (19) described drought is "a period of more than some particular number of days with precipitation less than some specified small amount' (p.2). (20)defined drought as the occasional and recurring situation with a strong reduction compared to the normal values of water availability for a significant period of time and over a wide area. Similarly, it is defined by (21) as a recurrent feature of climate that is characterized by temporary water shortages relative to normal supply, over an extended period a season, year, or several years, in a wide region.

Drought is commonly classified into; meteorological, agricultural, hydrological and socioeconomic droughts (22). Meteorological drought is a more common and natural event, whereas agricultural, hydrological and socioeconomic droughts emphasize more the human or social aspects (23). The sequence begins with meteorological drought; persistent, dry conditions may induce agricultural, hydrological and water resources droughts $(24,25)$.

\subsection{Drought Globally}

Drought has a major effect on cultivation in terms of decreases in economic activity, agricultural productivity and drinking water stock in life-threatening cases that has controlled the famine (26). The International Board on Climate Change has noted that the yearly average of waterway overflow and water disposal are projected to decline by $10 \%-13 \%$ over certain waterless and semiarid areas in normal and low-slung opportunities, snowballing the occurrence, strength, and duration of drought, along with its related impacts (27). Inopportunely many nations do not have satisfactory incomes deliver an early warning but need external funding to provide the essential early threatening evidence for risk management (28). Therefore, in an organized world, the essential for data on a global measure is critical for accepting the view of the failures in agricultural production, food safety, possible for civil battle and connected impacts on food prices (29).

Globally, given the expectation related to the universal climate change, might result from increasing drought problem. Kogan (30) conducted identify drought in order to knowledge comprehensive on the drought impacts in North America, Europe, and Australia, particularly for some region with the mainland affected by drought Allowing to the historical viewpoint by examining how the drought has varied over several regions of the world during the last millennium. Miyan (8) his study showed that many people impacted by the natural disaster in developed countries. They lost their economy and life from a natural disaster. One of the reasons behind natural disaster is drought. As reported, that the developing countries have more effect from natural disaster compared to the developed countries.

According to (31), severe droughts affected vast regions of Asia, with Western India, Southern and Central Pakistan. The Asian regions have been among the continual drought-prone regions of the world. Afghanistan, India, Pakistan and Sri Lanka have described droughts at least once in each three-year period in the past five periods. In 2012, Pakistan confirmed emergency in provinces Mirpur Khas and Tharparkar districts are in severe drought and many people had to be migrated (32). One of the important doubts with respect to rotation and rainfall with the present understanding of climate change in the monsoon regions remains. Therefore, in Asia has this drought problem until facing those societies. They have implemented the project. However, unable to satisfy of projects until suddenly change climate and water cycle (33).

\subsection{Drought in West Asia and North Africa (WA/NA)}

The drought has an increasingly common and major effect on human security located in arid areas of West Asia and North Africa (34). According to the Epidemiology and Centre of Research, the percentage of the population affected by drought $51 \%$ of all other disasters combined. This circumstance illustrates the severity of concern of drought. The WA/NA is the most affected region $83 \%$ in the world of the people in this area is unnatural by drought (35).

The West Asia/North Africa region is severely vulnerable to natural disasters such as, droughts, floods, earthquakes, heat waves and sandstorms, which leads to increased significantly economic and social losses because of the events of natural disasters (36). During the past three decades, most of the Arab regions are severely vulnerable to natural disasters such as, droughts, floods, earthquakes, heat waves and sandstorms. During the past three decades, the Arab region has faced an increase in natural disasters events, which amounted to more than 276 disasters, killing 100,000 , affecting 10 million and rendering nearly 1.5 million people homeless (37). Thus, drought is considered the major disaster among of all other disasters where it affects around 38.09 million people (38).

In addition to, Asia was associated with arid climate in 2000, because of drought, desertification, sandstorms and water scarcity. 
Agricultural zones were affected due to droughts which were estimated in rural and urban areas as more than 40 million hectares (14). On the other hand, through food and water shortages, drought is also thought to have caused the displacement of one million environmental refugees in Niger is 1985 (39) and 5 million in the African Sahel in 1995 (40). In 2000, in each of Sudan, Somalia and Kenya respectively 8, 6 and 3 million people who officially considered at hazard of famine, in addition to several million in other countries (41). As for losses of human life, for example, 450,000 deaths in Ethiopia and Sudan in 1984 directly attributed to drought (42).

In many Arab countries, droughts have become a more frequent and a serious bluster to humanitarian safety. It is a very hazardous problem, and will increase causing serious threat on various aspects of life, taking into account that most of the Arab states are suffering from frailty of their ecosystems, and facing intense risks of deterioration of vegetation cover, soil, and depletion of water resources on per day continuously. This is coupled with the rushing increase in population growth accompanied by an increase pressure on natural resources in this region (38). As the number of population in Arab world 125 million in 1970 to exceed 280 million in 2000 and it is expected that up to more than 500 million in 2030, and hence many countries are already living under water stress conditions (43). In addition to climate change, this is the major cause for the Arab region droughts. Climate models show that over the last 30 years temperatures in the Arab region have been increasing $50 \%$ faster than global averages. Climate changes will affects more than 340 million populations in the Arab zone. More than 100 million are poor and least able to resist these changes. Over the past three decades, nearly 50 million people were affected in the Arab region by climatic disasters events, with losses estimated at $\$ 11.5$ billion (5).

\subsection{Drought in Yemen}

To the best knowledge of the researcher, there is no scientific study on drought in Yemen, as well as the lack of numbers that accurately describe how the drought affects the Yemenis (7-9). However, there is information about the drought in Yemen found in non-local studies. These studies did not provide sufficient information on the drought in Yemen, they also did not address the sdrought indicators, through which on the duration, intensity and frequency of droughts in Yemen can be identified. What is reported in those studies is just general information, where no details about the causes, effects, and severity of drought in Yemen could touched.

What makes the matter even worse, Yemen is the poorest and least-developed country among the whole countries of the Middle East. In the recent years, Yemen has suffered from changes in rainfall patterns, higher temperatures and increased frequency of droughts. For example, the drought which took place in 19901991 had a significant effect on the socio-economic situation in Yemen, resulting in wide agricultural losses and a serious increase in the number of poor households in rural zones, and low revenue contribution of the agricultural production in the gross domestic product of the country(12).

According to U.S (7), Yemen climate was affected by drought during the periods $1967 / 69$ and 1972/74, which led to a threefold increase in food imports, despite the increase in agricultural production after the end of the drought in 1971. In 1983 and 1984, the Yemen's economy dropped significantly, as a result of the drought that prevailed over most of the country over that period. The drought-reduced total output of grain by more than half in 1983, but food availability remained at the normal level, due to the increased grain imports from outside the country. Generally, in 1983-1984 Yemen's agriculture dropped remarkably due to the severe drought (44).

Likewise, once again in 1990-91, the agricultural sector recorded substantial losses, because of the significant reduction in agricul- tural crops production and increased poverty in rural areas because of the drought (10). In addition, in the same period, the drought had dangerous reflections on the food security of a large segment of the population. In general, many studies have found that there is a significant lack of understanding and awareness of the drought and its effect, as well as the capacity of mitigating it in Yemen (12).

Additionally, there are a number of weaknesses in the drought management system in Yemen, including the lack of technical capacity to analyze drought data and processed, if any, difficulty to get data on drought, no a regional exchange of information on drought as there is no early warning system for drought monitoring (13). The drought of the period from 2007-2009 was the most influential which seriously damaged the socio-economic development in Yemen. It has become a real disaster sweeping the most areas of the country, leaving behind many of negative damages on the economy and society (8). (45) clarified that due to the water scarcity and severity drought in Yemen, the per capita water resource does not exceed 195 cubic meters per year. It is considerably less than the water poverty line of 1000 cubic meters per year. "Due to the lack of research, there are no numbers that accurately describe how drought is affecting Yemenis" (8). It has become a real disaster in Yemen. Due to the lack of studies, there are no specific numbers that accurately describe the drought in Yemen. Thus, we cannot know how drought affects the environment, economy, and society in Yemen.

\subsection{Drought in the Study Area}

A quite number of studies were carried out in the study area, some of these studies addressed Yemen in general, including the Tihama plain (study area), and some other of these studies addressed parts of the study area such as Hodiedah Governorate and a number of valleys in the study area. Those studies were from a variety of geographical, geological and hydrological topics. Some of those studies addressed the drought from different aspects and in a simple way, however, to the best knowledge of the researcher, there is no detailed and complete study of the drought in Yemen in general and the study area (Tihama plain) in particular.

The researcher could not find an integrated study about the drought in the study area. However, there is some simple information about the drought have been found in studies that talked about the study area from other perspectives. That information does not give a detailed description and accurate results about the drought, which can be relied upon in drought monitoring and mitigation in the study area. In addition, reports and news under natural or human headlines introduced some basic information on this issue which was not considered as completed investigation.

In Tihama plain, drought is one of the factors affecting soil formation and characteristics of vegetation, where the plants take thistles form and short weeds to be able to resistance drought. For example, the permanent drought which dominates the western part of the study area is not allowed to grow a good vegetarian cover with the exception of some plants which are capable of withstand the drought like Suaeda and Haloxylon plants. In addition to some annual weeds which grow during the rainy season, and because these plants are the main source for grazing in the western part of the study area. The occurrence of drought leads to deterioration of pastures and then the livestock exposure to danger (46). Drought is also the most important causes of environmental degradation in the region (47).

According to (48), the periods of the eighties and nineties and the first five years of the twenty-first century are among the most drought periods impact on the Tihama Plain. The study reported that the vegetation, soil, and groundwater are the most affected factors by drought. While another study about desertification in a part of Tihama plain reported that the drought of the most important factors causing desertification and land degradation in the region (49). 
As could be noted above, it is obvious that Yemen including the study area have been suffering from frequent drought, and numerous of social, environmental and economic problems as a result of the low precipitation rates and frequent droughts. In contrast, there is no previous detailed study or sufficient information about the drought in Yemen in general and Tihama plain in particular. Thus, there is an urgent need to study the drought in Yemen, in order to fill such a gap

\section{The study area and methodology}

\subsection{The study area}

Tihama Plain is located on the western part of Yemen between latitude $12^{\circ} .5-16^{\circ} .5$ north of the Equator and between longitude $42^{\circ} .5-43^{\circ} .5$ east of Greenwich, and lies about $226 \mathrm{~km}$ of the capital city, Sana'a. The study area covers a total area of $25,314.93 \mathrm{~km}^{2}$. Figure 1 shows the geographical location and the Tihama plain in the Yemen country.

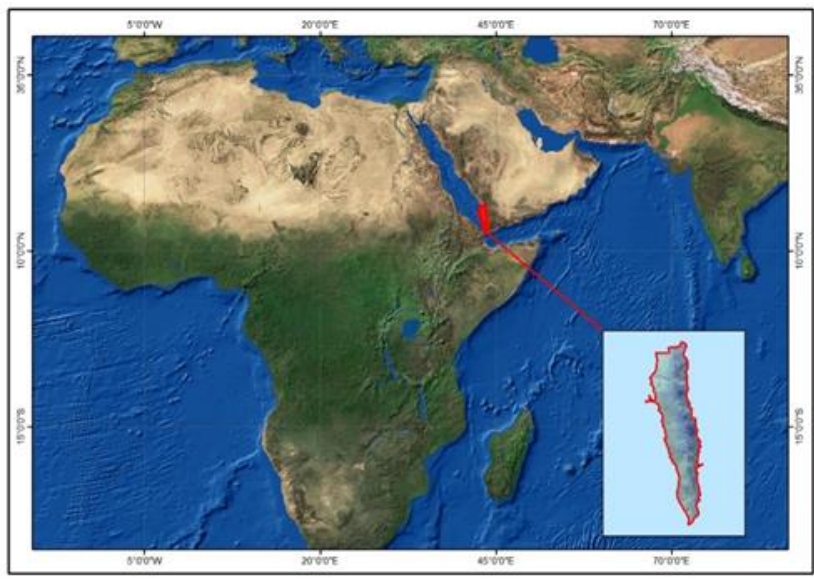

Figure 1: Location of the Study Area (Tihama Plain, Yemen)

The study area is a corrugated flat plain with few steep slopes (less than one degree) slowly tilted in the direction of the sea. The high area starts from sea level in the west to a height of about $250 \mathrm{~m}$ in the east, except for some peaks and mountain ledges, which range in height between $400 \mathrm{~m}$. The various morphologies and their heights affect the quantity of annual rainfall in the region, where the range of rainfall increases from about $50 \mathrm{~mm}$ at the coast in the west to more than $600 \mathrm{~mm}$ in the eastern parts, depending on the gradual rise of the surface area above sea level (48). The surface of the study area is penetrated by watercourses in the most important main valleys in Yemen (Moore, Surdud, Rmaa, Zabid, and Siham) from east to west, which made this region the most important agricultural areas in Yemen.

The study area has an arid and semi-arid climate; the rainfall in the region is low generally ranging between $50-600 \mathrm{~mm}$ per year. This is due to its location within trough of the Red Sea as well as the low-level topography of the surface compared to the neighbouring mountain blocks. In addition, the rainfall fluctuates from year to year depending on the conditions of the various pressure systems over the land areas and the adjacent surface water bodies.

Based on yearly precipitation, the study area is divided into three rainfall regions; arid region (western part) where the average rainfall is between $50-200 \mathrm{~mm}$ per year, semi-arid region (middle part) the annual rainfall $200-400 \mathrm{~mm}$, and semi-wet region (eastern part) $400-600 \mathrm{~mm}$ annually (48). Rain falls almost every month, however, heavy rains fall in the months (July, August and September) because these months are the summer months, which represents the main rainfall season over most land in Yemen. For this, reason the highest quantity of rainfalls on the study area in the summer. As for temperatures, the ranging $37^{\circ} \mathrm{C}$ in summer and $24^{\circ} \mathrm{C}$ in winter (50).

In this study, the NDVI index used to determine the changes of vegetation cover which was used to assess the drought. NDVI is one of the most important indicators available on a large scale. In addition, it is more reliable and used widely in monitoring and assessing droughts, at the same time, changes in sand dunes areas were also studied for the same purpose. The month of October was chosen each for 1985 and 2015 in order to assess the changes in the vegetation cover, because this month is considered as the growth month for vegetation. The same criterion was applied in order to assess changes in the sand dunes areas.

The determination of changes in the green spaces and dunes areas in the satellite images was done using GIS software 10.2. The study then calculated the natural changes in the indicator and then classified the results to drought categories, based on the values obtained. Two environmental indicators of drought, vegetation and sand dunes were monitored in this study.

\subsection{Vegetation}

Vegetation cover is a very strong environmental indicator of drought due to the negative correlation between rainfall amount and duration on the one hand, and vegetation density on the other. To monitor and assess the vegetation of the area, multi-temporal remote sensing data was used. Landsat Thematic Mapper (TM5) of October 1985 and Landsat Operational Land Imager (OLI8) of October 2015 were downloaded from the official website of the United State Geological Survey (USGS) via the Earth Explorer. The choice of 1985 and 2015 images (See Appendices A and B) was due to the need to assess the condition of both vegetation and sand dunes between these two periods as they mark the beginning and the end of the study periods. However, due to the problem of data availability, and lack of cloud free images for 1990, 1995 and 2010, only, the 1985 and 2015 images were used. The images were then subjected to pre-processing such as band stacking, haze and noise removal and conversion of digital number (DN) to reflectance values (RV) with aid of Erdas Imagine 2014 version image processing software. Later, Normalised Difference Vegetation Index (NDNI) was computed for the 2 images to highlight the vegetation condition of the study area in 1985 and 2015 .

NDVI is calculated using the formula:

$$
\mathrm{NDVI}=\frac{(\mathrm{NIR})-(\mathrm{RED})}{(\mathrm{NIR})+(\mathrm{RED})}
$$

Where:

NIR = The amount of near infrared light reflected by the vegetation and captured by the satellite sensor.

RED $=$ The amount of red light in the visible spectrum that is reflected by the vegetation and captured by the satellite sensor. Using Landsat 5 Image, NDVI is thus calculated as:

$$
\mathrm{NDVI}=\frac{(\text { Band } 4-\text { Band3 })}{(\text { Band } 4+\text { Band } 3)}
$$

While using Landsat 8 OLI image it is calculated as:

$$
\text { NDVI }=\underline{(\text { Band } 5-\text { Band } 4)}
$$

(Band5 + Band4) 
This is based on the fact that, healthy vegetation will absorb most of the visible light that falls on it, and reflects a large portion of the near-infrared light. Unhealthy or sparse vegetation reflects more visible light and less near-infrared light. Bare soils on the other hand reflect moderately in both the red and infrared portion of the electromagnetic spectrum. The NDVI algorithm subtracts the red reflectance values from the near-infrared and divides it by the sum of near-infrared and red bands. Theoretically, NDVI values are represented as a ratio ranging in value from -1 to 1 but in practice extreme negative values represent water, values around zero represent bare soil and values over 0.6 represent dense green vegetation. NDVI has been widely used to study changes in the spatial pattern of vegetation (51)

\subsection{Sand Dunes}

This is another environmental indicator of drought due to the positive correlation between rainfall amount and duration on one hand, and sand dune deposit on the other. The same images, Landsat Thematic Mapper (TM5) of October 1985 and Landsat Operation- al Land Imager (OLI8) of October 2015 were used in monitoring and assessing sand dune deposit in the study area. After the afore mentioned pre-processing, appropriate band combinations were used to discriminate and highlight sand dunes from other land cover types for visual observations. Green, near infrared and short wave infrared bands corresponding to bands 2, 4, and 7 for Landsat TM 5 and bands 3, 5, and 7 for Landsat OLI 8 were used. These bands show high reflective variability of desert surface and therefore easily highlight sand deposits. Later, colour composite images were produced and using enhancement techniques such as contrast stretching and spatial filtering spatial information contained in the two images were enhanced making it easy to identify dunes as they stand out clearer and brighter. On-screen digitizing of dune was then performed in ArcGIS 10.3 environment. A vector file was later created that contained the locations and number of digitized dunes. Subsequently, the vector file was used to create a continuous surface of dune density maps through interpolation in ArcGIS environment. This was later used to calculate relative percentage of dune deposit in each year. Figure 2 summarized the major steps involve in this research.

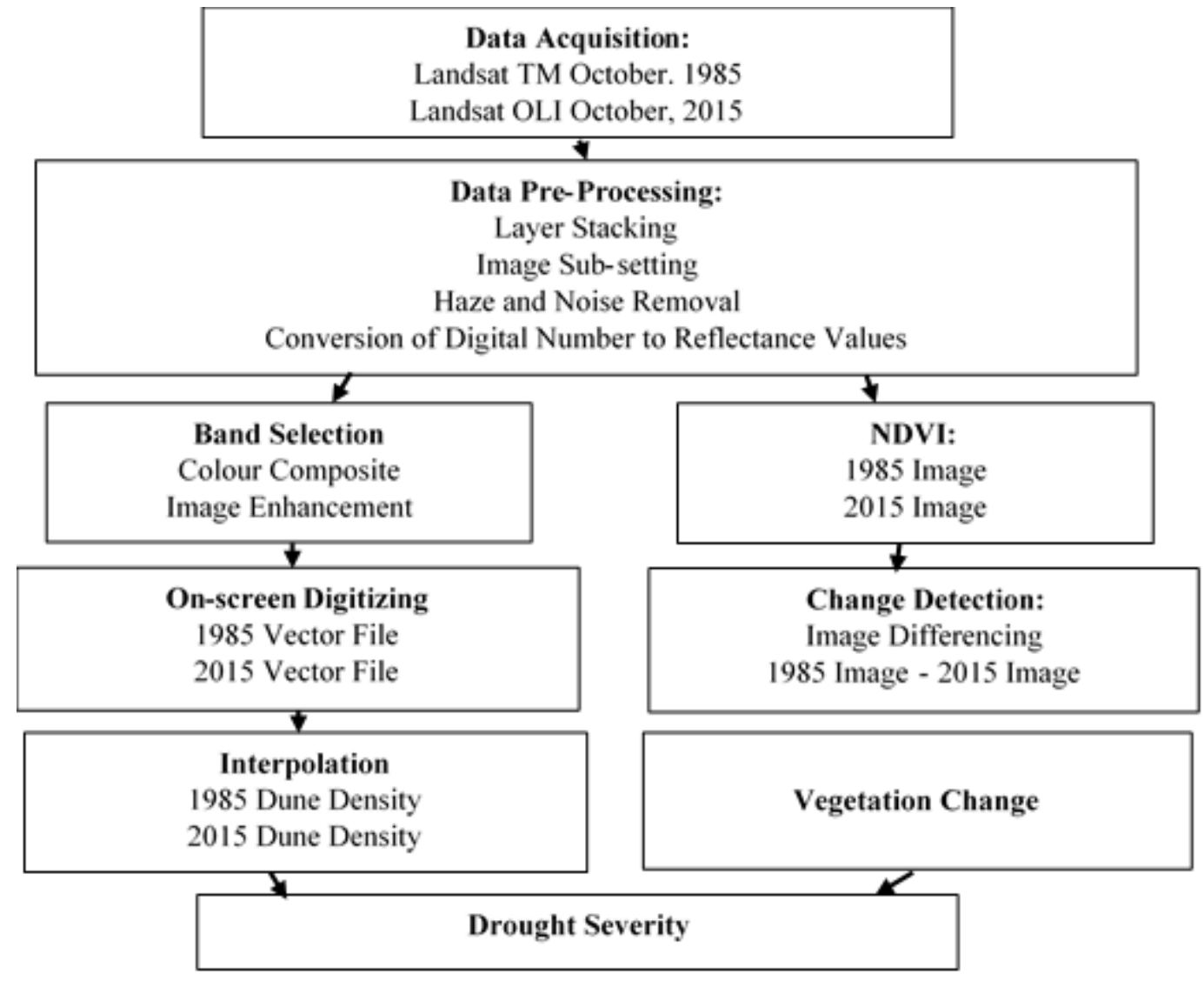

Figure 2. Flowchart of the Research Methodology on Environmental Indicators

\section{Results and Findings}

This research considers two basic environmental indicators of drought which are: Normalized Difference Vegetation Index (NDVI) and sand dune deposit to measure drought intensity in the area. This is due to the negative correlations that exist between NDVI and drought and a positive correlation between drought and sand dunes deposit (52).

\section{Normalized Difference Vegetation Index (NDVI)}

NDVI is one of the environmental indicators of drought due to the positive correlation between rainfall amount and duration on one hand, and the vegetation density on the other. That is, the higher the amount and duration of the rainfall in a particular area, the more dense the vegetation in that area would be. NDVI data of 1985 and 2015 shows a progressive increase in the intensity of drought in the area. Between 1985 to 2015 , there is 26 percent increase in the area under severe drought from 3,452.87 square kilometres in 1985 to 4,341.14 square kilometres in 2015. Similarly, the area under moderate drought also increased from 7,943.31 square kilometres in 1985 to 13,048.54 square kilometres in 2015, representing almost 64 percent increase. On the other hand, areas under mild drought and those receiving normal rain experienced a decrease during the period as they gradually transformed into mild and severe drought situations. In 1985, a total land area of 7,534.79 square kilometres was experiencing mild drought, but this has declined to only 4,352.23 square kilometres in 2015 representing over 73 percent decrease which is transformed to moderate and severe drought conditions. Also, of the total of 6,009.1 kilometer square of land that received relatively normal rainfall in

1985 , about 38 percent $(2,872.22$ kilometres square) have been transformed to a drought condition (see Table 1 and Figure 3 ). 
Table1: Area $\left(\mathrm{km}^{2}\right)$ and percentage (\%) of drought intensity using NDVI

\begin{tabular}{|l|c|c|c|c|}
\hline $\begin{array}{l}\text { NDVI/Drough } \\
\text { t }\end{array}$ & $\begin{array}{c}\text { Area in } \\
\mathbf{1 9 8 5}\end{array}$ & $\begin{array}{c}\text { Area in } \\
\mathbf{2 0 1 5}\end{array}$ & $\begin{array}{c}\text { Difference } \\
\mathbf{k m}^{\mathbf{2}}\end{array}$ & $\begin{array}{c}\text { Percent- } \\
\text { age \% }\end{array}$ \\
\hline $\begin{array}{l}\text { Severe } \\
\text { Drought }\end{array}$ & 3452.87 & 4341.14 & 888.27 & $\begin{array}{c}26(\text { In- } \\
\text { crease) }\end{array}$ \\
\hline $\begin{array}{l}\text { Moderate } \\
\text { Drought }\end{array}$ & 7943.31 & 13048.54 & 5.105 .23 & $\begin{array}{c}64(\text { In- } \\
\text { crease) }\end{array}$ \\
\hline Mild Drought & 7534.79 & 4352.23 & 5.513 .75 & $\begin{array}{l}73(\mathrm{De}- \\
\text { crease) }\end{array}$ \\
\hline No Drought & 6009.1 & 3136.88 & 2.872 .22 & $\begin{array}{l}38(\mathrm{De}- \\
\text { crease) }\end{array}$ \\
\hline
\end{tabular}

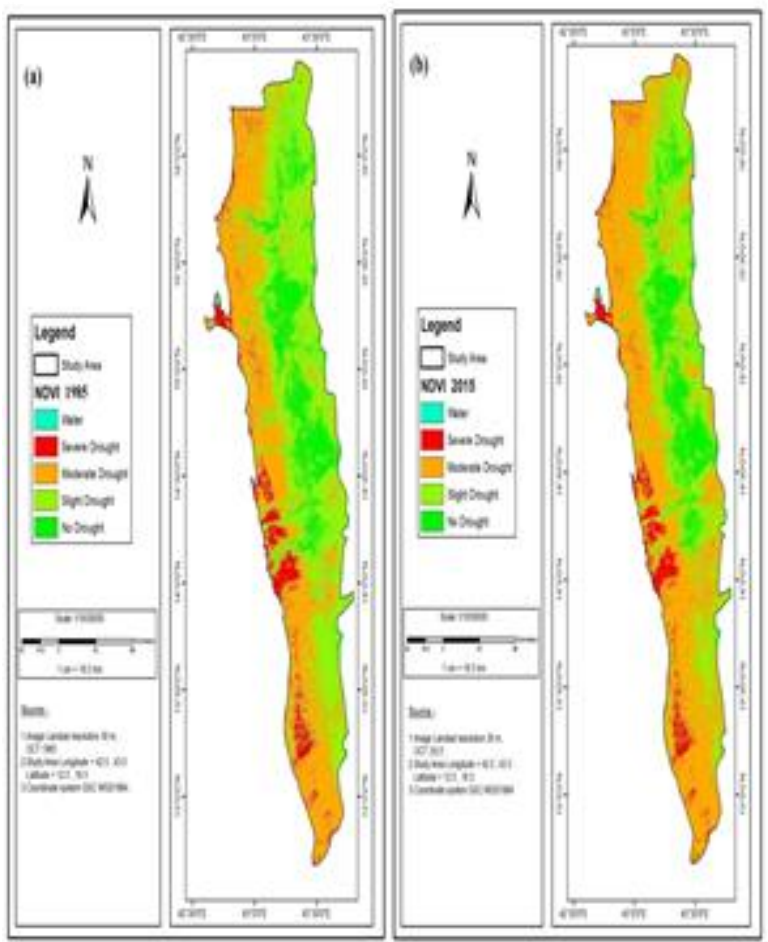

Figure 3. Drought Severitv using NDVI (a) 1985.

\section{Sand Dunes}

Sand dunes deposit is yet another environmental indicator of drought. This is due to the negative correlation that exists between rainfall and vegetation on one hand and sand dunes deposit on the other (52). That is, the higher the amount and duration of rainfall, the more densely the vegetation cover will be, and thus, the lower the sand dunes deposit. On the other hand, areas with lower amount and shorter duration of rainfall, will in turn, have a relatively little or no vegetation cover, which also makes the soil more prone to erosion, transportation and deposition by the wind. This results in increased sand dunes deposit in the area. The result of this study shows that, there is a progressive increase in the area covered by sand dunes within the study period.

During the year 1985, of the total of 25,314.93 square kilometres of land in the study area, only about 2,761.42 square kilometres, representing 11 percent was covered by the sand dunes. This has however, increased to 4,809.1 square kilometres representing 19 percent of the total land area in the year 2015. This means that, within the 30 years study period, the total land area covered by the sand dunes has expanded from 2,761.42 square kilometres in 1985 to 4,809.1 square kilometres in 2015 representing over 74 percent increase. This situation suggests that there is an increasing trend in the intensity of drought in the study area over this period (see Table 2 and Figure 4).

Table 2: Area and percentage of sand dunes

\begin{tabular}{|l|c|c|}
\hline Year & Area $\left(\mathbf{k m}^{\mathbf{2}}\right)$ & Percentage \% \\
\hline $\mathbf{1 9 8 5}$ & 2761.42 & 11 \\
\hline $\mathbf{2 0 1 5}$ & 4809.1 & 19 \\
\hline Difference & 2047.68 & 74 \\
\hline
\end{tabular}

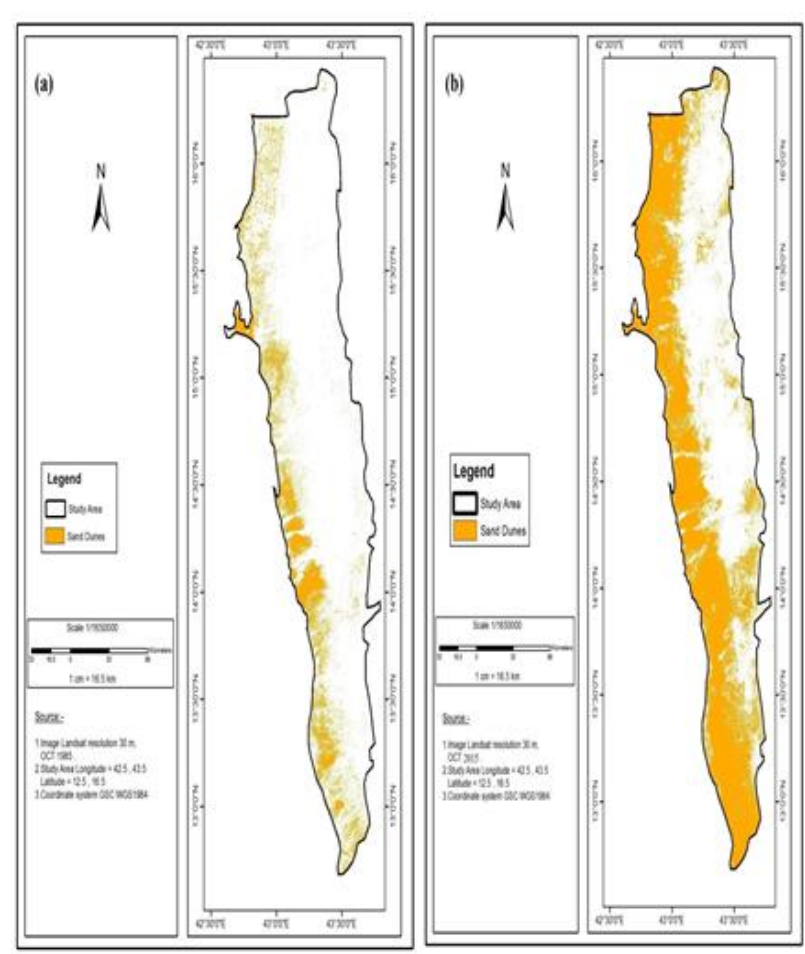

Fig 4: Drought Severity using Sand Dunes (a) 1985, (b) 201

\section{Conclusion}

The analysis of the above environmental indicators clearly depicts an increasing trend in the drought intensity in the study area. NDVI shows progressive decline in vegetation cover and gradual transition of areas from mild to moderate drought (64\%) and from moderate to severe drought $(26 \%)$. Within the study period, the area also recorded $74 \%$ increase in sand dunes deposit. These environmental indicators therefore confirm the assertion that, drought intensity is on the increase in the study area. Moreover, unless both the individuals put concerted effort and measures in place, as well government and private organisations to arrest this ugly trend, it will continue to pose a major threat and challenges to both food security and overall development of the country. Finally, it is recommended that, the government should seriously look into the drought issue through improving resource management practices and development of drought assessment and implementation unit to help minimize the adverse effects of drought. In doing this, concerned authorities should work closely with stakeholders who might be directly or indirectly affected by drought. Socioeconomic data should also be taken into consideration when assessing drought risk to better understand the vulnerable groups.

\section{References}

[1] Kirono D, Kent D, Hennessy K, Mpelasoka F. Characteristics of Australian droughts under enhanced greenhouse conditions: Results from 14 global climate models. Journal of arid environments. 2011;75(6):566-75.

[2] Keyantash J, Dracup JA. The quantification of drought: an evaluation of drought indices. Bulletin of the American Meteorological Society. 2002;83(8):1167-80.

[3] Shahid S, Behrawan H. Drought risk assessment in the western part of Bangladesh. Natural Hazards. 2008;46(3):391-413.

[4] Dinar A, Keck A. Water supply variability and drought impact and mitigation in sub-Saharan Africa. Drought: A Global Assessment. 2000;2:129-48

[5] Verner D. Adaptation to a changing climate in the Arab countries: a case for adaptation governance and leadership in building climate resilience: World Bank Publications; 2012.

[6] Kaniewski D, Van Campo E, Weiss H. Drought is a recurring challenge in the Middle East. Proceedings of the National Academy of Sciences. 2012;109(10):3862-7. 
[7] U.S. . Agricultural Sector Assessment in Yemen Arab Republic: Agency for International Development \& Ministry of Agriculture of Yemen Sana'a,

Yemen http://pdf.usaid.gov/pdf_docs/pnaa1964.pdf; 1982.

[8] Miyan MA. Droughts in Asian least developed countries: Vulnerability and sustainability. Weather and Climate Extremes. 2015;7:823.

[9] UNITED-NATIONS. Drought management planning in waterscarce and in-transitioning-settings countries in West Asia/North Africa. Beirut, Lebanon. : 2013.

[10] ESCWA. Water Development Report 1: Vulnerability of the Region to Socio-Economic Drought. New York: United Nation, http://www.escwa.un.org/information/publications/edit/upload/sdpd -05-9-e.pdf 2005

[11] Wiebelt M, Breisinger C, Ecker O, Al-Riffai P, Robertson R, Thiele R. Climate change and floods in Yemen: impacts on food security and options for adaptation. International Food Policy Research Institute (IFPRI), 2011

[12] ESCWA/UN-DESA. Drought management planning in waterscarce and in-transitioning-settings countries in West Asia/North Africa. Beirut, Lebanon. https://sustainabledevelopment.un.org/content/documents/2156Dro ught_EGM_Working_Draft_Background_Paper_21June13.pdf. 2013.

[13] Bogan N. Effective Drought Management For Sustained Livelihoods in the Middle East: Duke University, Durham, North Carolina; 2014.

[14] Mishra AK, Singh VP. A review of drought concepts. Journal of Hydrology. 2010;391(1):202-16.

[15] Chin W. DROUGHT CYCLES AND WEATHER PATTERNS Canadian Water Resources Journal. 1978;3(1):68-84.

[16] Wilhite DA. Drought Preparedness and Response in the Context of Sub-Saharan Africa. Journal of contingencies and crisis management. 2000;8(2):81-92

[17] Wilhite DA, Hayes MJ, Knutson C, Smith KH. Planning for drought: Moving from crisis to risk management. JAWRA Journal of the American Water Resources Association. 2000;36(4):697-710.

[18] Linsley RKJMAKaJLHS. Applied Hydrology. McGraw Hill, New York1959.

[19] Palmer WC. Keeping track of crop moisture conditions, nationwide: The new crop moisture index. 1968.

[20] Rossi G. Tools for drought mitigation in Mediterranean Regions Springer Science \& Business Media; 2003.

[21] Wilhite DA. Drought monitoring as a component of drought preparedness planning. Coping with Drought Risk in Agriculture and Water Supply Systems: Springer; 2009. p. 3-19.

[22] AMS. Statement on meteorological drought. Bulletin of the American Meteorological Society. 2004;85:771-3.

[23] Eklund L, Seaquist J. Meteorological, agricultural and socioeconomic drought in the Duhok Governorate, Iraqi Kurdistan. Natura Hazards. 2015;76(1):421-41.

[24] Andreadis KM, Clark EA, Wood AW, Hamlet AF, Lettenmaier DP Twentieth-century drought in the conterminous United States. Journal of Hydrometeorology. 2005;6(6):985-1001.

[25] Vidal JP, Wade S. A multimodel assessment of future climatological droughts in the United Kingdom. International Journal of Climatology. 2009;29(14):2056-71.

[26] Roy AK, Hirway I. Multiple impacts of droughts and assessment of drought policy in major drought prone states in India. Gujarat, India: Centre for Development Alternatives. 2007.

[27] Pozzi W, Sheffield J, Stefanski R, Cripe D, Pulwarty R, Vogt JV, et al. Toward global drought early warning capability: Expanding international cooperation for the development of a framework for monitoring and forecasting. Bulletin of the American Meteorological Society. 2013;94(6):776-85.

[28] Cavatassi R, Lipper L, Narloch U. Modern variety adoption and risk management in drought prone areas: insights from the sorghum farmers of eastern Ethiopia. Agricultural Economics. 2011;42(3):279-92.

[29] Forster P, Jackson L, Lorenz S, Simelton E, Fraser E, Bahadur K Food security: near future projections of the impact of drought in Asia. The Centre for Low Carbon Futures. 2012.

[30] Kogan FN. Global drought watch from space. Bulletin of the American Meteorological Society. 1997;78(4):621-36.

[31] Eriyagama N, Smakhtin V, Gamage N. Mapping drought patterns and impacts: a global perspective: Iwmi; 2009.

[32] Tsubo M, Fukai S, Basnayake J, Ouk M. Frequency of occurrence of various drought types and its impact on performance of photoperiod-sensitive and insensitive rice genotypes in rainfed lowland conditions in Cambodia. Field Crops Research. 2009;113(3):287-96.
[33] Hazell P. Managing drought risks in the low-rainfall areas of the Middle East and North Africa. Cornell University, Ithaca, New York, USA. 2007.

[34] Karrou M, El Mourid M. Drought management and planning strategies in semi-arid and arid agro-pastoral systems of West Asia and North Africa: A review. Options Méditerranéennes Série A: Séminaires Méditerranéens. 2008.

[35] El Kharraz J, El-Sadek A, Ghaffour N, Mino E. Water scarcity and drought in WANA countries. Procedia Engineering. 2012;33:14-29.

[36] World-Bank. Natural Disasters in the Middle East and North Africa: A Regional Overview. Disaster Risk Management Unit Middle East and North Africa. Washington DC 20433 http://www.uncclearn.org/sites/default/files/inventory/wb164.pdf. 2014.

[37] Erian W. Drought vulnerability in the Arab Region. Case studyDrought in Syria. Ten years of scarce water (2000-2010). Arab Center for the Studies of Arid Zones and Dry Lands and the United Nations, secretariat of the International Strategy for Disaster Reduction. 2011.

[38] Erian W. Drought Vulnerability in the Arab Region Special Case Study: Syria (Geneva: United Nations International Strategy for Disaster Risk Reduction, 2010). Shahrzad Mohtadi,"Climate Change and the Syrian Uprising," Bulletin of the Atomic Scientists. 2012:5.

[39] Gemenne F. Climate-induced population displacements in a $4 \mathrm{C}+$ world. Philosophical Transactions of the Royal Society of London A: Mathematical, Physical and Engineering Sciences. 2011:369(1934):182-95.

[40] Myers N. Environmental refugees: a growing phenomenon of the 21st century. Philosophical Transactions of the Royal Society B: Biological Sciences. 2002;357(1420):609.

[41] Myers N, Kent J. Food and hunger in sub-Saharan Africa. Environmentalist. 2001;21(1):41-69.

[42] Guha-Sapir D, Hargitt D, Hoyois P. Thirty years of natural disasters 1974-2003: The numbers: Presses univ. de Louvain; 2004.

[43] United-Nations. . Population and development report. First issue: Water scarcity in the Arab world. New York: 2003.

[44] USDA. Middle East and North Africa. Situation and Outlook Report. United States Department of Agriculture, Economic Research Service. Washington https://searchworks.stanford.edu/view/3929918. 1986.

[45] Noaman A, Petersen G, Kiesel J, Wade S. Climate Change Impacts on Water Resources in Yemen. Journal of Earth Science and Engineering. 2013;3(9):629.

[46] Hussein YA. AL-Hodeidah Governorate - Geographical Study. : Sana'a University, Yemen; 1989.

[47] Taher HR. Deterioration of ecological relationships in the Red Sea Coast: Sana'a University, Yemen; 2004.

[48] Abdullah YA. Environmental problems associated with climate in the middle part of Tihama plain in Yemen republic using GIS: Cairo University, Egypt; 2010.

[49] DhaifAllah AAA. Spatial Variation of desertification in Hodeidah Governorate: Thamar University, Yemen.; 2012.

[50] Assage AM. Climate in Yemen- Study of the Climate geography. Ebadi Center for Studies and Publications: Sana'a University. Yemen; 1998.

[51] Zhou D, Zhao X, Hu H, Shen H, Fang J. Long-term vegetation changes in the four mega-sandy lands in Inner Mongolia, China. Landscape ecology. 2015;30(9):1613-26.

[52] Karnieli A, Agam N, Pinker RT, Anderson M, Imhoff ML, Gutman GG, et al. Use of NDVI and land surface temperature for drought assessment: Merits and limitations. Journal of climate. 2010;23(3):618-33. 